\title{
17.
}

\section{NOTE ON MR BRONWIN'S PAPER ON ELLIPTIC INTEGRALS.}

[From the Cambridge Mathematical Journal, vol. III. (1843), pp. 197-198.]

This Note was in answer to objections raised by $\mathrm{Mr}$ Bronwin in his paper "On Elliptic Functions" Camb. Math. Jour. vol. III. (1843) pp. 123--131, to some of the formulæ of transformation in the Fundamenta Nova. There is in it a serious error which was afterwards pointed out by $\mathrm{Mr}$ Bronwin. The Note is omitted, as are also the other papers, [18] and part of [21], which refer to the same subject. 